\title{
Enhanced Recovery After Surgery: Are We Ready, and Can We Afford Not to Implement These Pathways for Patients Undergoing Radical Cystectomy?
}

\author{
Hitendra R.H. Patel ${ }^{a, *}$, Yannick Cerantola $^{b}$, Massimo Valerio $^{b}$, Beata Persson $^{c}$, \\ Patrice Jichlinski $^{b}$, Olle Ljungqvist ${ }^{d}$, Martin Hubner ${ }^{e}$, Wassim Kassouf $^{f}$, Stig Müller ${ }^{g}$, \\ Gabriele Baldini $^{h}$, Francesco Carli ${ }^{h}$, Torvind Naesheim ${ }^{i}$, Lars Ytrebo ${ }^{i}$, Arthur Revhaug ${ }^{j}$, \\ Kristoffer Lassen $^{j}$, Tore Knutsen ${ }^{a}$, Erling Aarsaether ${ }^{a}$, Peter Wiklund ${ }^{k}$, James W.F. Catto ${ }^{l}$

\begin{abstract}
${ }^{a}$ Department of Urology, University Hospital of Northern Norway, Tromsø, Norway; ${ }^{\mathrm{b}}$ Department of Urology, University Hospital of Lausanne, Lausanne, Switzerland; ' Department of Urology, University Hospital of Örebro, Örebro, Sweden; ${ }^{\mathrm{d}}$ Department of Surgery, University Hospital of Örebro, Örebro, Sweden; ${ }^{\mathrm{e}}$ Department of Visceral Surgery, University Hospital of Lausanne, Lausanne, Switzerland; ${ }^{\mathrm{f}}$ Department of Urology, McGill University, Montreal, Canada; ${ }^{\mathrm{g}}$ Department of Urology, Akershus University Hospital, Lørenskog, Oslo, Norway; ${ }^{\mathrm{h}}$ Department of Anesthesia, McGill University, Montreal, Canada; ${ }^{\mathrm{i}}$ Department of Anesthesia E' Intensive care, University Hospital of Northern Norway, Tromsø, Norway; ${ }^{\mathrm{j}}$ Department of GI Surgery, University Hospital of Northern Norway, Tromsø, Norway; ${ }^{\mathrm{k}}$ Department of Urology, Karolinska University Hospital, Stockholm, Sweden; ${ }^{1}$ Academic Urology Unit, University of Sheffield, Sheffield, UK
\end{abstract}

Despite anesthetic and surgical improvements in recent decades, postoperative morbidity remains a common drawback of major surgery. One of the main pathogenic factors leading to morbidity is the surgical stress response. A better understanding of this cascade mediated by the central nervous system, resulting in a systemic release of stress hormones and inflammatory mediators, has led to the development of care pathways attempting to reduce this response. Although no single element can eliminate postoperative morbidity and mortality, a combination of changes could likely reduce postoperative morbidity and lower hospital costs. The concept of a fast track recovery was introduced in the 1990s. It was found that applying evidence-based perioperative principles to patients undergoing open colonic surgery could halve the rate of postoperative complications and shorten the length of stay (LOS) in the hospital [1].

This multimodal perioperative care pathway has evolved into enhanced recovery after surgery (ERAS). The initial changes have been complemented by a multitude of measures with proven or probable impact on the surgical stress response. Current ERAS protocols include $>20$ elements (Fig. 1) and reduce both morbidity and LOS [1]. To assist the transfer from colonic surgery, members of the
ERAS Society who perform radical cystectomy undertook a systematic review of the evidence for ERAS in this field [2]. We highlighted a paucity of high-quality evidence within this field and now wish to encourage clinicians to report their own findings and to undertake high-quality trials of ERAS items for this procedure.

Radical cystectomy represents a significant surgical challenge to patients [3]. Despite the standardization of surgical technique, the introduction of robotic laparoscopic assistance [4], and improved anesthesia and perioperative care protocols, the morbidity after radical cystectomy (with bilateral pelvic lymph node dissection and urinary diversion or bladder reconstruction) is between $30 \%$ and $64 \%$, even in high-volume centers $[5,6]$. Cystectomy patients are mostly elderly and comorbid (many with smoking-related cardiovascular and pulmonary diseases). They are therefore ideal candidates for an ERAS pathway that reduces surgical stress and complications. However, an uncritical application of the guidelines issued from colorectal surgery [7] seems inappropriate because the surgical procedure (small bowel anastomosis, urine within the peritoneal cavity, both extra- and intraperitoneal access) and morbidity of the patients differs between these cohorts.

\footnotetext{
* Corresponding author. Department of Urology, University Hospital of Northern Norway, Sykehusvegen 38, Tromsø, Norway. Tel. +44 7980846772; Fax: +44 3076377076.

E-mail address: urology@hrhpatel.org (H.R.H. Patel).
}

0302-2838/\$ - see back matter (C) 2013 Published by Elsevier B.V. on behalf of European Association of Urology.

http://dx.doi.org/10.1016/j.eururo.2013.10.011 


\begin{tabular}{|c|c|c|c|c|}
\hline ERAS Item & Summary & Specifics for Radical Cystectomy patients & $\begin{array}{l}\text { Evidence for Cystectomy / } \\
\text { Rectal surgery }\end{array}$ & $\begin{array}{l}\text { Recommendation } \\
\text { grade }\end{array}$ \\
\hline $\begin{array}{l}\text { 1. Preoperative counseling } \\
\text { and education }\end{array}$ & $\begin{array}{l}\text { Patients should receive dedicated preoperative } \\
\text { counseling and education }\end{array}$ & $\begin{array}{l}\text { Surgical details, hospital stay and discharge } \\
\text { criteria in oral and written form. Stoma } \\
\text { education. Patient's expectations }\end{array}$ & NA / Low & Strong \\
\hline \multirow[t]{4}{*}{$\begin{array}{l}\text { 2. Preoperative medical } \\
\text { optimization }\end{array}$} & $\begin{array}{l}\text { Preoperative optimization of medical conditions } \\
\text { should be recommended. }\end{array}$ & Correction of anemia and co-morbidities & NA / Moderate & Strong \\
\hline & Preoperative nutritional support should be & Nutritional support & NA / High & Strong \\
\hline & considered, especially for malnourished patients & $\begin{array}{l}\text { Smoking cessation and alcohol reduction } 4 \\
\text { weeks prior to surgery }\end{array}$ & NA / Moderate & Strong \\
\hline & & Encouraging physical exercise & NA / Very low & Strong \\
\hline $\begin{array}{l}\text { 3. Oral mechanical bowel } \\
\text { preparation }\end{array}$ & $\begin{array}{l}\text { Preoperative bowel preparation can be safely } \\
\text { omitted }\end{array}$ & & Moderate / High & Strong \\
\hline $\begin{array}{l}\text { 4. Preoperative carbohydrate } \\
\text { loading }\end{array}$ & $\begin{array}{l}\text { Preoperative oral carbohydrate loading should } \\
\text { be administered to all non-diabetic patients }\end{array}$ & & NA / Low & Strong \\
\hline 5. Preoperative fasting & $\begin{array}{l}\text { Clear fluid intake until } 2 \mathrm{hrs} \text { and solids food until } \\
6 \mathrm{hrs} \text { before general anesthesia. }\end{array}$ & & NA / Moderate & Strong \\
\hline 6. Preanasthesia medication & Avoidance of long-acting sedatives & & NA / Moderate & Strong \\
\hline \multirow[t]{2}{*}{ 7. Thrombosis prophylaxis } & $\begin{array}{l}\text { Patients should wear well-fitting compression } \\
\text { stockings and receive pharmacological } \\
\text { prophylaxis with LMWH. Leave } 12 \mathrm{~h} \text { interval } \\
\text { between injections and epidural manipulation. }\end{array}$ & Cystectomy patients are considered at high risk. & NA / High & Strong \\
\hline & $\begin{array}{l}\text { LMWH Extended prophylaxis for } 4 \text { weeks should } \\
\text { be carried out in patients at risk }\end{array}$ & $\begin{array}{l}\text { Prolonged prophylaxis should therefore be } \\
\text { administered. }\end{array}$ & NA / High & Strong \\
\hline 8. Epidural analgesia & $\begin{array}{l}\text { Thoracic epidural analgesia is superior to } \\
\text { systemic opioids in relieving pain. It should be } \\
\text { continued for } 72 \mathrm{~h}\end{array}$ & & NA / High & Strong \\
\hline $\begin{array}{l}\text { 9. Minimally invasive } \\
\text { approach }\end{array}$ & $\begin{array}{l}\text { Try to use in a trial setting. Long term oncological } \\
\text { results awaited. }\end{array}$ & $\begin{array}{l}\text { Laparoscopic/robotic cystectomy is } \\
\text { recommended inside a trial setting until long } \\
\text { term results are available. }\end{array}$ & Low / Moderate & Strong \\
\hline 10. Resection site drainage & $\begin{array}{l}\text { Perianastomotic and/or pelvic drain can be } \\
\text { safely omitted }\end{array}$ & $\begin{array}{l}\text { Because of urine leak, drainage might be } \\
\text { required in cystectomy patients }\end{array}$ & NA / Low & Weak \\
\hline \multirow[t]{2}{*}{$\begin{array}{l}\text { 11. Antimicrobial prophylaxis } \\
\text { and skin preparation }\end{array}$} & $\begin{array}{l}\text { Patient should receive a single dose } \\
\text { antimicrobial prophylaxis } 1 \mathrm{~h} \text { before skin incision. }\end{array}$ & & NA / High & Strong \\
\hline & $\begin{array}{l}\text { Skin preparation with chlorexidine- alcohol } \\
\text { prevents / decreases surgical site infection. }\end{array}$ & & NA / Moderate & Strong \\
\hline $\begin{array}{l}\text { 12. Standard anesthetic } \\
\text { protocol }\end{array}$ & $\begin{array}{l}\text { To attenuate the surgical stress response, } \\
\text { intraoperative maintenance of adequate } \\
\text { hemodynamic control, central and peripheral } \\
\text { oxygenation, muscle relaxation, depth of } \\
\text { anesthesia, and appropriate analgesia is } \\
\text { recommended. }\end{array}$ & & NA / Moderate & Strong \\
\hline $\begin{array}{l}\text { 13. Perioperative fluid } \\
\text { management }\end{array}$ & $\begin{array}{l}\text { Fluid balance should be optimized by targeting } \\
\text { cardiac output using the esophageal Doppler } \\
\text { system. Avoid overhydration. Judicious use of } \\
\text { vasopressors is recommended with arterial } \\
\text { hypotension. }\end{array}$ & & Low / Moderate & Strong \\
\hline $\begin{array}{l}\text { 14. Preventing intraoperative } \\
\text { hypothermia }\end{array}$ & $\begin{array}{l}\text { Normal body temperature should be maintained } \\
\text { per-and postoperatively. }\end{array}$ & $\begin{array}{l}\text { Especially relevant for cystectomy patients since } \\
\text { operative duration is prolonged }\end{array}$ & NA / high & Strong \\
\hline 15. Nasogastric intubation & $\begin{array}{l}\text { Post-operative nasogastric intubation should not } \\
\text { be used routinely }\end{array}$ & Early removal or no NGT is recommended & Low / High & Strong \\
\hline \multirow[t]{2}{*}{ 16. Urinary drainage } & $\begin{array}{l}\text { Transurethral catheter is removed as early as } \\
\text { possible after pelvic surgery in patients with a } \\
\text { low risk of urinary retention }\end{array}$ & $\begin{array}{l}\text { Ureteral stents and transurethral neo-bladder } \\
\text { catheter should be used. The optimal duration of } \\
\text { ureteral stenting (at least until POD 5?) and } \\
\text { transurethral catheterization is unknown. }\end{array}$ & Very low / Low & Weak \\
\hline & No transurethral catheter if Ileal Conduit & & Very low / Low & Strong \\
\hline $\begin{array}{l}\text { 17. Prevention of } \\
\text { postoperative ileus }\end{array}$ & $\begin{array}{l}\text { Multimodal approach to optimize gut function. } \\
\text { Involve gum chewing and oral magnesium }\end{array}$ & & Moderate / Moderate & Strong \\
\hline 18. Prevention of PONV & $\begin{array}{l}\text { Multimodal PONV prophylaxis in all patients with } \\
\geq 2 \text { risk factors. }\end{array}$ & Multimodal prophylaxis & $\begin{array}{l}\text { Very low / Low (High in high } \\
\text { risk patients) }\end{array}$ & Strong \\
\hline 19. Postoperative analgesia & $\begin{array}{l}\text { Multimodal postoperative analgesia, include } \\
\text { thoracic epidural anlagesia }\end{array}$ & & NA / High & Strong \\
\hline 20. Early mobilization & Early mobilization should be encouraged & $\begin{array}{l}2 \mathrm{hrs} \text { out of bed same day of surgery (POD } 0 \text { ). } \\
6 \mathrm{hrs} \text { out of bed POD } 1\end{array}$ & NA / Low & Strong \\
\hline 21. Early oral diet & Oral nutrition started $4 \mathrm{hrs}$ after surgery & & NA / Moderate & Strong \\
\hline 22. Audit & $\begin{array}{l}\text { All patients should be audited for compliance } \\
\text { and outcomes }\end{array}$ & $\begin{array}{l}\text { Audit outcomes, cost effectiveness, compliance } \\
\text { and protocol changes }\end{array}$ & NA / Low & Strong \\
\hline
\end{tabular}

Abbreviations

NA: Not applicable (missing). LMWH: Low molecular weight heparin. POD: Post-operative day. NGT: Nasogastric tube. PONV: post-operative nausea and vomiting

Fig. 1 - Enhanced recovery after surgery (ERAS) elements applied to radical cystectomy. Reproduced with permission from the ERAS Society, Clinical Nutrition, and e-SPEN [2].

The successful use of modified ERAS protocols has been reported for radical cystectomy. For example, Maffezzini et al. applied 6 of 22 ERAS items (no oral mechanical bowel preparation, epidural analgesia, antimicrobial prophylaxis, standard anesthetic protocol, preventing intraoperative hypothermia, and early nasogastric tube removal) to 71 patients undergoing radical cystectomy. When compared with historical controls, patients with ERAS had a reduced 
time to diet (average from $7 \mathrm{~d}$ to $4 \mathrm{~d}$ ) and shorter LOS (from $22 \mathrm{~d}$ to $15 \mathrm{~d}$ ) without worsening morbidity [8].

Arumainayagam et al. compared 56 consecutive patients undergoing open radical cystectomy with standard perioperative care with 56 patients after implementation of ERAS (including 7 of 22 items: no bowel preparation, no preoperative fasting, epidural analgesia, postoperative nausea and vomiting [PONV] prophylaxis, early oral nutrition, early mobilization, and early removal of abdominal drain [9]). Morbidity and time to first bowel movement was similar in the two groups, but LOS was significantly reduced (from 17 $\mathrm{d}$ to $13 \mathrm{~d}$ ) in the enhanced recovery group.

Pruthi et al. reported the implementation of ERAS after cystectomy ( 9 of 22 items: preoperative information, deep vein thrombosis prophylaxis, antibiotics prophylaxis, early removal of nasogastric tube, early oral nutrition, early mobilization, prevention of PONV, prevention of ileus, and postoperative analgesia) in 262 patients [10]. When compared with historical controls, the most recent 100 patients had better postoperative recoveries.

Donat et al. combined early nasogastric tube removal with metoclopramide in 27 patients compared with 54 controls. Complication and LOS rates were similar in both groups, but the intervention group had an earlier return to bowel sounds and tolerance of diet [11]. By combining thoracic epidural analgesia, early nasogastric tube removal, early oral nutrition, and mobilization in 15 prospective patients, Brodner et al. showed a reduction of the time to first defecation, with no difference with regard to morbidity or LOS when compared with 15 patients undergoing a standard care plan [12].

Several components of ERAS are critical during surgery. One example is intraoperative fluid replacement (type, timing, and volume) during major surgery. Although some authors advocate standardized restricted fluid replacement, others propose goal-directed regimens. Metaanalysis of Doppler-guided intraoperative fluid management suggests this latter approach produces fewer postoperative complications and shorter LOS than others [13]. As such, ERAS guidelines advocate intraoperative normovolemia and intraoperative fluid therapy based on pulsus paradoxus for abdominal surgery in high-risk patients [7]. This consensus was recently supported by data from radical cystectomy [14]. This randomized controlled trial (RCT) revealed that low intraoperative fluid regimens were associated with lower transfusion and fluid replacement requirements, and subsequently better clinical outcomes.

ERAS pathways clearly improve patient care, reduce morbidity, and shorten LOS. All studies evaluating elements of the ERAS care pathways in radical cystectomy have found benefits in postoperative morbidity, return to bowel function, or LOS. However, none have applied a full ERAS protocol (of the 22 items) to radical cystectomy patients. Thus the benefits of a full ERAS pathway remain unknown. Although the body of evidence for the use of ERAS protocols in cystectomy patients is increasing rapidly, drawbacks remain. For instance, most studies are of limited quality and are either underpowered or retrospective. Some surgeons have criticized the initial results of ERAS RCTs, arguing that the improved outcome was mainly due to the so-called Hawthorne effect [15]. It is therefore mandatory to measure clinical outcomes in a standardized manner to provide the highest and most reliable evidence. Also, compliance with the protocols is important and requires an initial increased workload at implementation (which might be considered a drawback). Finally, there is a need for standardization and adaptation of protocols tailored to the surgical specifics of the respective specialty. Such protocols are not yet widely available. Prospective auditing is more likely to prove efficiency than more randomized trials, which might be considered unethical today. Because they are highly complex and impossible to blind against, ERAS protocols are not particularly well suited for randomized designs, although it is possible [16].

Multicenter prospective studies using a centralized database will help answer questions such as the optimal perioperative nutritional support; the need, type, and duration of pelvic and urinary catheterization; and the real benefits of full ERAS protocols on morbidity, mortality, LOS, readmission rate, and costs. The ERAS Society has created a group focused on developing ERAS for major urologic procedures, starting with radical cystectomy. A review of the literature and the evidence forming a basis for a protocol has been assembled [1] and is available online (www. erassociety.org). In line with the previous work produced by the society, this guideline will be tested in a multicenter evaluation. We now welcome interested urologists to join and help further these developments for our patients.

Conflicts of interest: The authors have nothing to disclose.

\section{References}

[1] Cerantola Y, Valerio M, Persson B, et al. Guidelines for perioperative care after radical cystectomy for bladder cancer: Enhanced Recovery After Surgery (ERAS $\mathbb{R})$ Society recommendations. Clin Nutr. In press.

[2] Adamina M, Kehlet H, Tomlinson GA, Senagore AJ, Delaney CP. Enhanced recovery pathways optimize health outcomes and resource utilization: a meta-analysis of randomized controlled trials in colorectal surgery. Surgery 2011;149:830-40.

[3] Hautmann RE, Abol-Enein H, Davidsson T, et al. ICUD-EAU International Consultation on Bladder Cancer 2012: urinary diversion. Eur Urol 2013;63:67-80.

[4] Khan MS, Elhage O, Challacombe B, et al. Long-term outcomes of robot-assisted radical cystectomy for bladder cancer. Eur Urol 2013; 64:219-24.

[5] Shabsigh A, Korets R, Vora KC, et al. Defining early morbidity of radical cystectomy for patients with bladder cancer using a standardized reporting methodology. Eur Urol 2009;55:164-76.

[6] Roth B, Birkhäuser FD, Zehnder P, et al. Parenteral nutrition does not improve postoperative recovery from radical cystectomy: results of a prospective randomised trial. Eur Urol 2013;63:475-82.

[7] Lassen K, Soop M, Nygren J, et al. Consensus review of optimal perioperative care in colorectal surgery: Enhanced Recovery After Surgery (ERAS) Group recommendations. Arch Surg 2009;144: 961-9.

[8] Maffezzini M, Gerbi G, Campodonico F, Parodi D. Multimodal perioperative plan for radical cystectomy and intestinal urinary 
diversion. I. Effect on recovery of intestinal function and occurrence of complications. Urology 2007;69:1107-11.

[9] Arumainayagam N, McGrath J, Jefferson KP, Gillatt DA. Introduction of an enhanced recovery protocol for radical cystectomy. BJU Int 2008;101:698-701.

[10] Pruthi RS, Nielsen M, Smith A, Nix J, Schultz H, Wallen EM. Fast track program in patients undergoing radical cystectomy: results in 362 consecutive patients. J Am Coll Surg 2010;210:93-9.

[11] Donat SM, Slaton JW, Pisters LL, Swanson DA. Early nasogastric tube removal combined with metoclopramide after radical cystectomy and urinary diversion. J Urol 1999;162:1599-602.

[12] Brodner G, Van Aken H, Hertle L, et al. Multimodal perioperative management-combining thoracic epidural analgesia, forced mobilization, and oral nutrition-reduces hormonal and metabolic stress and improves convalescence after major urologic surgery. Anesth Analg 2001;92:1594-600.
[13] Rahbari NN,Zimmermann JB, Schmidt T, Koch M, Weigand MA, Weitz J. Meta-analysis of standard, restrictive and supplemental fluid administration in colorectal surgery. Br J Surg 2009;96:331-41.

[14] Wuethrich PY, Studer UE, Thalmann G, Burkhard F. Intraoperative continuous norepinephrine infusion combined with restrictive deferred hydration significantly reduces the need for blood transfusion in patients undergoing open radical cystectomy: results of a prospective randomized trial. Eur Urol. In press. http://dx.doi.org/ 10.1016/j.eururo.2013.08.046

[15] Nygren J, Thacker J, Carli F, et al. Guidelines for perioperative care in elective rectal/pelvic surgery: Enhanced Recovery After Surgery (ERAS $®$ ) Society recommendations. World J Surg 2013;37:285-305.

[16] Karl A, Buchner A, Becker A, et al. A new concept for Early Recovery After Surgery in patients undergoing radical cystectomy for bladder cancer-results of a prospective randomized study. J Urol. In press. http://dx.doi.org/10.1016/j.juro.2013.08.019

Would you like to receive all the benefits of EAU membership, but have no time for tedious paperwork?

\section{Becoming a member is now fast and easy!}

\section{Go to www.uroweb.org and click EAU membership to apply online. It will only take you a couple of minutes to submit your application, the rest - is for you to enjoy!}

